\title{
Mobile Ad Hoc Routing Protocols - A Comparative Performance Analysis by Diversifying the Nodes
}

\author{
Vijayalakshmi.P \\ Assistant Professor, \\ Department of Computer \\ Applications, \\ Karunya University, \\ Coimbatore, Tamilnadu, India
}

\author{
Dr.V.Saravanan \\ Director, \\ Department of Computer \\ Applications, \\ N.G.P Institute of \\ Technology, Coimbatore, \\ Tamilnadu, India.
}

\author{
Dr. P. Ranjit Jeba \\ Thangaiah \\ Assistant Professor (SG), \\ Department of Computer \\ Applications, \\ Karunya University, \\ Coimbatore, Tamilnadu, India
}

\author{
Abraham Dinakaran. J \\ Assistant Professor, \\ Department of Computer \\ Applications, \\ Karunya University, Coimbatore, \\ Tamilnadu, India
}

\begin{abstract}
Mobile Ad hoc network is self-organizing and adaptive in nature. An Ad hoc wireless network does not rely on any fixed network entities the network itself is essentially infrastructure less. However, due to the presence of mobility, routing information changes to reflect subsistence in link connectivity. This paper highlights the performance of routing protocols like AODV, DSDV, DSR and TORA based on various evaluating parameter metrics like routing overload, throughput, average end-to-end delay, Packet Delivery Fraction (PDF) etc., by increasing the number of nodes when nodes are in mobile and tend to route the packets from source to destination. The simulation analysis proves that these metrics vary with different values in different test scenarios by diversifying the nodes.
\end{abstract}

\section{Keywords}

MANETs, Average End-to-End Delay, Throughput, Packet Delivery Fraction, Routing Overhead, Normalized Routing Load, AODV, DSDV, TORA, DSR.

\section{INTRODUCTION}

A Mobile Ad Hoc Network (MANET) is defined as a collection of mobile platforms or nodes where each node is free to move about arbitrarily [1]. Each node logically consists of a router that may have multiple hosts and that also may have multiple wireless communication devices that are connected to other networks.

MANETs are also characterised by a dynamic, random and rapidly changing topology. This makes the routing algorithms fail to perform correctly, since they are not robust enough to accommodate such a changing environment [2]. Consequently, more research papers came to existence showing the optimal routing algorithms to deliver the packets (data) from source to destination.

As MANET is an infrastructureless network, the routing process is managed by the routing protocols. Routing is the process of selecting paths in a network between any two nodes acting as source and a destination and to send the data. Routing protocol is the routing of packets based on the defined rules and regulations [3]. Every routing protocol has its routing algorithms which correspondingly discovers the route and also maintains it. A routing metric is a value used by a routing algorithm to determine whether one route should perform better than another [3]. Metrics are listed as throughput, delay, route overhead and PDF.

\section{RELATED WORK}

Mostly Mobile Ad Hoc Networks (MANETs) are used in military communication purposes that attain major challenges in wireless networks. Many routing protocols are proposed to route the packets with the shortest distance from source to destination that plays a major issue when nodes move frequently from one place to another in a network environment. A lot of research works are done on design of efficient routing protocols and analysing the energy consumption model and CBR model. In [2], the performance of I-DSDV is compared with DSDV and concludes that I-DSDV is superior to DSDV in performance. Also I-DSDV is compared with AODV routing protocol and proven that it is better than AODV protocol in Packet Delivery Fraction but lower in end-to-end delay and Routing overhead hence resulting performance of I-DSDV is lower when compared with AODV. In [3], comparative performance analysis of DSDV, AODV, and DSR routing protocols is done and concluded that DSDV has very low throughput and high routing load when compared with AODV and DSR. The original motivation in the design of Dynamic Source Routing (DSR) came from the Address Resolution Protocol (ARP) [10] which was used in TCP/IP suite of protocols in the internet. This ARP usage can be found in Ethernets and other types of networks for finding the link layer MAC address of a node which is on the same subnet as the sender. ARP uses ARP REQ (Request) and ARP REPLY (Reply) in finding the local IP 
address and the related MAC address. DSR protocol extends the behaviour of ARP by allowing the ROUTE REQUEST instead of ARP REQUEST. In 1994, DSR protocol was designed with basic operation like route maintenance and route discovery mechanism. Later in 1996, DSR was improved with additional design details with few simulation results. Later on a number of other protocols have also been structured under similar route discovery and route maintenance mechanism. A few examples of such protocols are Signal Stability-Based Adaptive Protocol (SSA) [12] and ABR [11] which discovers route on-demand with a similar mechanism of DSR with only difference of selecting long-lived links between the nodes for avoiding breakage of nodes in shorter duration. The Associativity Based Routing (ABR) protocol adds an extra overhead for monitoring the link stability of periodic beacon packets. Another OnDemand routing protocol with mechanism similar to DSR is Ad Hoc On-Demand Distance-Vector (AODV) [9], [13] where the route discovery and route maintenance are same but the routes are hop-by-hop instead of source routing. If a link breakage occurs when the route is active, the route initiates a Route Error (RERR) message to the source node to intimate the breakage so that the source node if still desires the route then it can reinitiates route discovery. In Zone Routing Protocol (ZRP) [14], [15] protocol defines a "routing zone" around each and every individual node. For routing between zones an on-demand protocol like DSR is used and for routing within zones a proactive protocol like distance-vector or link-state is used. The routing zone reduces the overhead of route discovery but adds overhead in maintaining the zone membership and routing information within each zone. During high mobility since an ondemand protocol is used for routing between zones, the ZRP may fail in successful packet delivery.

\section{ROUTING ALGORITHMS (DSDV, AODV, DSR, TORA)}

Routing protocols for ad hoc networks are broadly classified as Link-state and Distance Vector Protocols. The DSDV is typically a pro-active routing protocol which maintains a table to store the routing information. Each node will maintain a routing table in which all of the possible destinations within the network and the number of hops to each destination are recorded [2]. Each entry in the routing table is marked with a sequence number which will avoid the formation of loops. In a very large population of mobile nodes, adjustments will likely be needed for the time between broadcasts of the routing information packets [2]. To reduce the amount of information carried in these packets, two types of route packets are used. The first is the full dump packet carries all available routing information and these packets are transmitted in frequently manner. The second packet is the incremental packets which are used to carry the information that has changed since the last full dump [1]. AODV (Ad-Hoc on Demand Distance Vector) is a source initiated routing protocol. It is reactive protocol as it only requests a route when needed and does not require nodes to maintain routes to the destination that are not actively used in communication [3][7].AODV is an improvement on DSDV because it typically minimizes the number of required broadcasts by creating routes on on-demand basis. So AODV classify it as a pure on-demand route acquisition system, as nodes that are not on a selected path do not maintain routes information or participate in routes table exchanges. Path discovery or route discovery in AODV is done by a Route
Request (RREQ) packet that is sent to its neighbours and a Route Reply (RREP) packet received as acknowledgement by the neighbour that first received the RREQ [4]. The route discovery process is done in AODV by when a node needs a route to a destination, it broadcasts a RREQ. Any nodes with a current route to that destination can unicast a RREP back to the source node. Sequence numbers are used to eliminate stale routes. Route information is stored in route table [1]. If a node receives more than one RREP packets for some destination from different nodes in the network then a node will chose the shortest route to destination [3]. DSR [6], [8] is an on demand routing protocol which was designed especially for multihop wireless ad hoc networks of mobile nodes. Though the design of the protocol is simple, it provides an efficient and excellent performance for routing in multihop wireless ad hoc networks. In DSR without any existence of network infrastructure and administration, the network can be self-organised and can selfconfigure. This protocol consists of two mechanisms namely route discovery and route maintenance of source routes.

Each packet in DSR carries full address (i.e.) details of each and every hop in the route from source to destination. This is one of the disadvantages of DSR which will not be effective in large networks as the amount of overhead in each packet will continue to increase as the network diameter increases. But still this protocol has an advantage over a few routing protocols such as AODV, LMR [4] and TORA [5] which performs better in moderate sized networks. Another added advantage of DSR is route cache, in which the protocol can store multiple routes in route cache so that the source node can check the cache either during a link breakage or before the route discovery process for a valid route. Since the route cache stores the route for longer time, this is very beneficial for network with low mobility. Another major advantage is that DSR does not need periodic beacons or hello messages, hence leading the nodes to sleep mode for conservation of power. This characteristic of DSR also saves the usage of bandwidth in the network. The Temporally Ordered Routing Algorithm (TORA) is a distributed routing algorithm based on the concept of link reversal [5]. TORA is applicable for highly dynamic mobile networking environment; the main objective of TORA is to limit the control message propagation in the highly dynamic mobile computing environment. In TORA each node has to explicitly initiate a query when it needs to send data to a particular destination, and it won't support a shortest-path computation.

TORA having 3 basic functions:

1) Creation of a route from source to destination.

2) Maintenance of the route.

3) Erasure of the route when the route is no longer valid.

TORA will provide multiple routes for any desired source/destination pair [8]. TORA attempts to build what is known as a Directed Acyclic Graph (DAG). DAG won't contain any cycles that means that there will be a route from source to destination and there is no way back. In route creation and maintenance phase, node use a height metric to establish a DAG rooted at the destination, and the links are assigned a direction 
(upstream or downstream) based on the relative height metric of neighboring nodes [1].When the nodes are moving the DAG route will broke and route maintenance is necessary to reestablish a DAG rooted at the destination [1], [6]. The timing is an important factor for TORA because the height metric is dependent on the logical time of the link failure. TORA assumes all nodes having synchronized clocks, this will accomplished via GPS [1]. TORA having three kinds of messages: The query message for creating a route, The UDP message for both creating and maintaining routes, The CLR message for erasing the route [9]. Advantages: Multiple paths are created, works well in dense networks, it is Loop free. Disadvantages: Not much used Since DSR, AODV outperform TORA, Not scalable by any means, and will not support shortest path computation.

\section{SIMULATION AND RESULTS DISCUSSION}

This paper reviews about the performance of AODV, DSR, DSDV and TORA protocols. NS-2.34 is the simulation tool used.

\subsection{Topologies used:}

The topography used is of $500 \times 500$ with $25,35,45,55,65,75,85,100$ nodes. We increase the number of nodes while keeping the total area constant, thus increasing the density. The transmission range is $250 \mathrm{mts}$.

\subsection{Average End-to-End delay :}

Average end to end delay, the performance of DSR and AODV are almost uniform. However, the performance of DSDV is degrading due to increase in the number of nodes. In TORA, the end-to-end delay varies as the change in number of nodes.

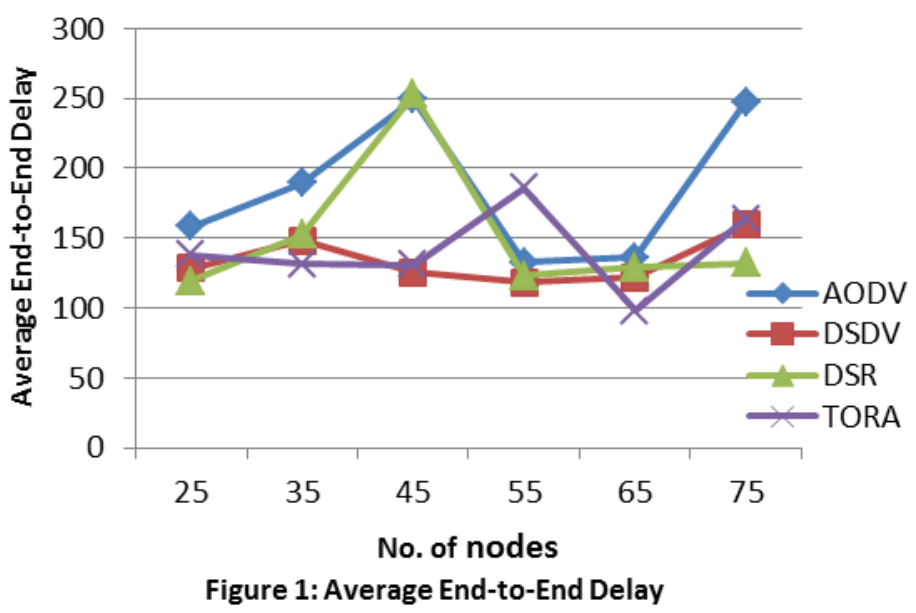

\subsection{Packet Delivery Fraction (PDF):}

In terms of PDF, DSR performs well when the number of nodes is less as the nodes increase performance declines. The performance of DSDV is better with more number of nodes. The performance of AODV is consistently uniform. PDF changes rapidly when number of nodes increases.

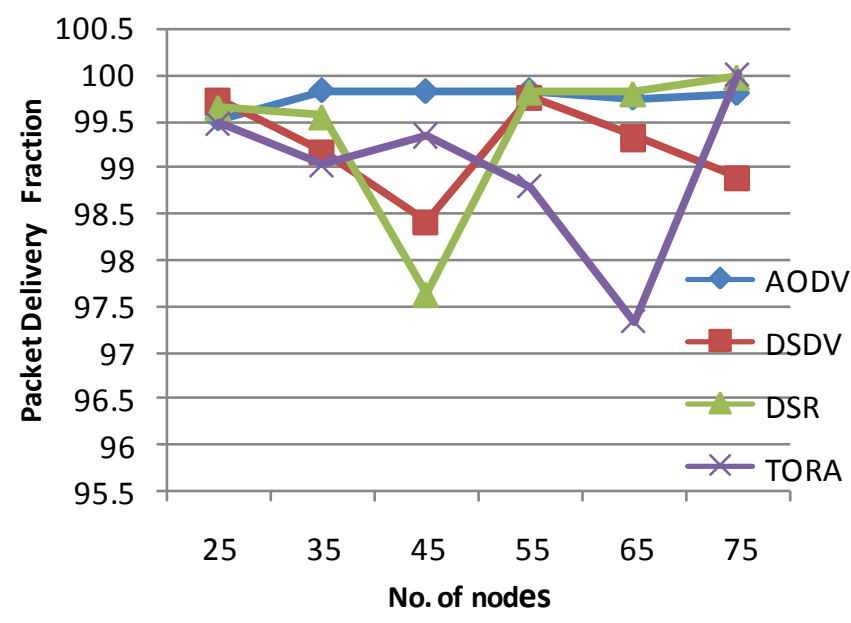

Figure 2: Packet Delivery Fraction (PDF)

\subsection{Routing Overhead (RO):}

In terms of routing overhead the performance of DSR is consistent. AODV is decreasing in comparison with DSDV as it tremendously increases.

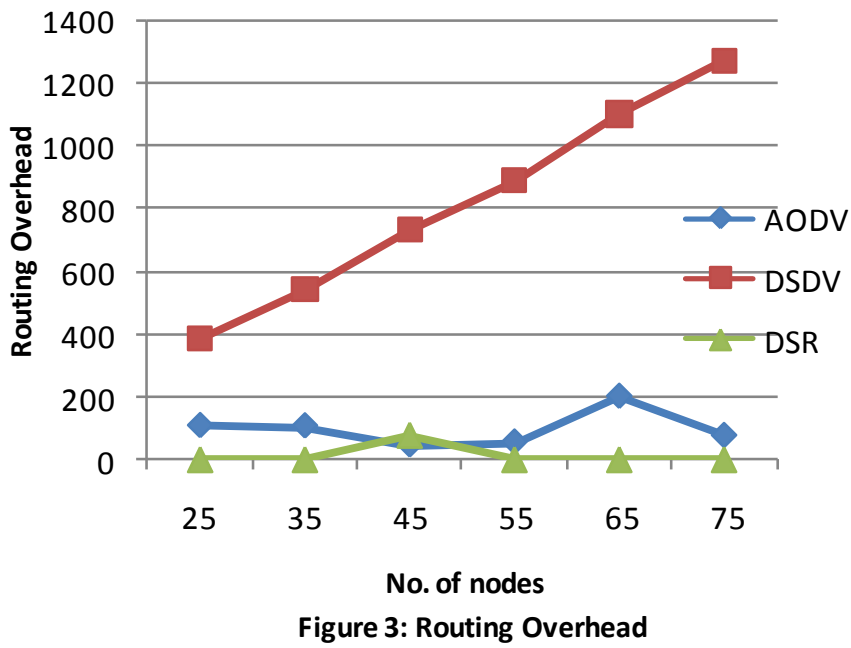

\subsection{Throughput:}

In terms of throughput, DSR remains consistent. AODV and DSDV toggle with respect to increase in number of nodes. In TORA, throughput changes rapidly with respect to number of nodes. 


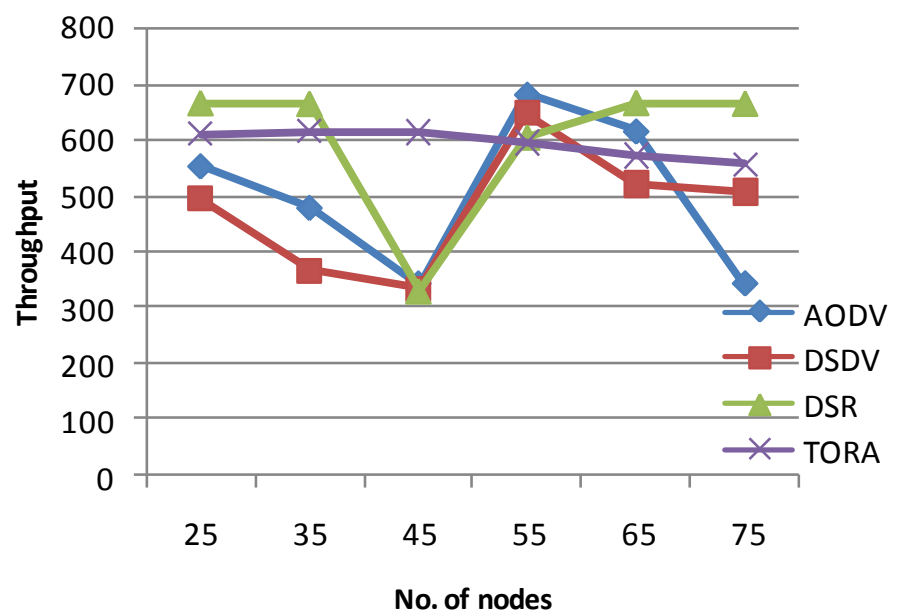

Figure 4: Throughput function

\subsection{Normalized Routing Load (NRL):}

In terms of Normalized Routing Load, AODV performs well even the nodes are increased in comparison with DSDV and DSR.

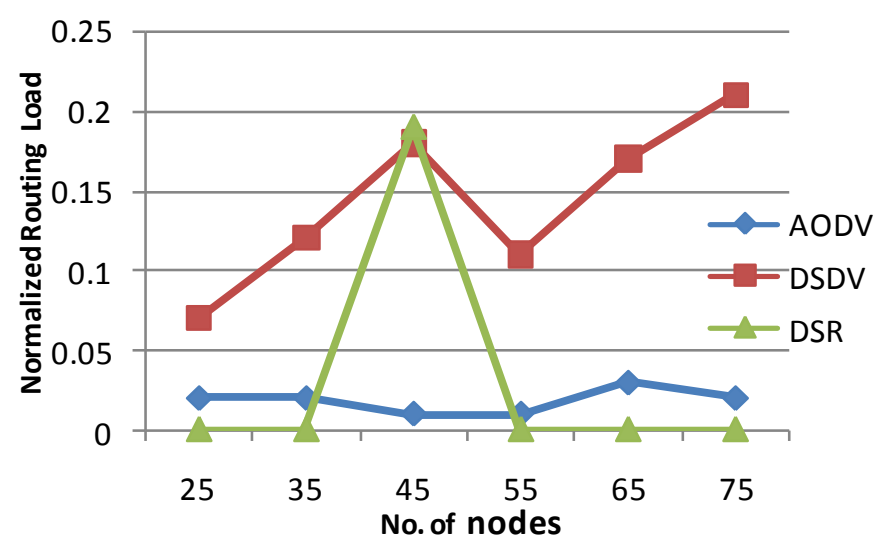

Figure 5: Normalized Routing Load

The following tables show the simulation results of AODV, DSR, DSDV and TORA protocols with the performance metrics:

TABLE -1 PERFORMANCE RATE (PACKET SIZE=1600BYTES, NO: OF NODES $=25$, MOBILITY=10.0MS)

\begin{tabular}{|l|l|l|l|l|l|l|l|}
\hline & PACKET & $\begin{array}{l}\text { PACKET } \\
\text { RECEIVE }\end{array}$ & PDF & $\begin{array}{l}\text { THROU } \\
\text { GHPUT }\end{array}$ & $\begin{array}{l}\text { END- } \\
\text { END }\end{array}$ & NRL & RO \\
\hline AODV & 6970.00 & 6936.00 & 99.51 & 551.94 & 158.57 & 0.02 & 108.00 \\
\hline DSDV & 5894.00 & 5877.00 & 99.71 & 494.00 & 128.26 & 0.07 & 385.00 \\
\hline DSR & 5241.00 & 5222.00 & 99.64 & 663.93 & 119.41 & 0.00 & 2.00 \\
\hline TORA & 2755.00 & 2740.00 & 99.46 & 613.24 & 137.78 & - & - \\
& & & & & & & \\
\hline
\end{tabular}

TABLE-2 PERFORMANCE RATE (PACKET SIZE=1600BYTES, NO: OF NODES $=35$, MOBILITY=10.0MS)

\begin{tabular}{|c|c|c|c|c|c|c|c|}
\hline & $\begin{array}{l}\text { PACKET } \\
\text { SENT }\end{array}$ & $\begin{array}{l}\text { PACKET } \\
\text { RECEIV } \\
\text { E }\end{array}$ & PDF & $\begin{array}{l}\text { THROU } \\
\text { GHPUT }\end{array}$ & $\begin{array}{l}\text { END- } \\
\text { END } \\
\text { DELAY }\end{array}$ & NRL & RO \\
\hline AODV & 6008.00 & 5997.00 & 99.82 & 477.11 & 189.70 & 0.02 & $\begin{array}{l}107.0 \\
0\end{array}$ \\
\hline$\overline{\text { DSDV }}$ & 4632.00 & 4593.00 & 99.16 & 365.25 & 148.01 & 0.12 & $\begin{array}{l}545.0 \\
0\end{array}$ \\
\hline DSR & 2155.00 & 2145.00 & 99.54 & 662.62 & 152.18 & 0.00 & 2.00 \\
\hline TORA & 2051.00 & 2031.00 & 99.02 & - & 131.32 & - & - \\
\hline
\end{tabular}

TABLE-3 PERFORMANCE RATE (PACKET SIZE=1600BYTES, NO: OF NODES $=45$, MOBILITY=10.0MS)

\begin{tabular}{|l|l|l|l|l|l|l|l|}
\hline & PACKET & PACKET & PDF & $\begin{array}{l}\text { THROUG } \\
\text { HPUT }\end{array}$ & $\begin{array}{l}\text { END- } \\
\text { END }\end{array}$ & NRL & RO \\
SENT & RECEIVE & & & & \\
\hline AODV & 4297.00 & 4289.00 & 99.81 & 341.26 & 249.31 & 0.01 & 46.00 \\
\hline DSDV & 4026.00 & 3962.00 & 98.41 & 334.42 & 125.44 & 0.18 & 732.00 \\
\hline DSR & 418.00 & 408.00 & 97.61 & 330.13 & 252.89 & 0.19 & 78.00 \\
\hline $\begin{array}{l}\text { TORA } \\
(47 \\
\text { nodes }\end{array}$ & 752.00 & 747.00 & 99.34 & 611.50 & 130.82 & - & - \\
\hline
\end{tabular}


TABLE-4 PERFORMANCE RATE (PACKET SIZE=1600BYTES, NO: OF NODES $=55$, MOBILITY=10.0MS)

\begin{tabular}{|l|l|l|l|l|l|l|l|}
\hline & PACKET & PACKET & PDF & $\begin{array}{l}\text { THROU } \\
\text { GHPUT }\end{array}$ & $\begin{array}{l}\text { END- } \\
\text { END }\end{array}$ & NRL & RO \\
\hline AODV & 8571.00 & 8556.00 & 99.82 & 680.74 & 132.74 & 0.01 & 55.00 \\
\hline DSDV & 8157.00 & 8137.00 & 99.75 & 647.20 & 118.32 & 0.11 & 891.00 \\
\hline DSR & 8351.00 & 8335.00 & 99.81 & 603.04 & 123.40 & 0.00 & 2.00 \\
\hline TORA & 1635.00 & 1615.00 & 98.78 & 592.52 & 185.66 & - & - \\
& & & & & & & \\
\hline
\end{tabular}

TABLE-5 PERFORMANCE RATE (PACKET SIZE=1600BYTES, No:OF NODES =65, MOBILITY=10.0MS)

\begin{tabular}{|l|l|l|l|l|l|l|l|}
\hline & PACKET & PACKET & PDF & $\begin{array}{l}\text { THROU } \\
\text { GHPUT }\end{array}$ & $\begin{array}{l}\text { END- } \\
\text { END }\end{array}$ & NRL & RO \\
\hline AODV & 7745.00 & 7725.00 & 99.74 & 614.62 & 136.42 & 0.03 & 202.00 \\
\hline DSDV & 6600.00 & 6555.00 & 99.32 & 521.32 & 122.16 & 0.17 & 1104.00 \\
\hline DSR & 6763.00 & 6749.00 & 99.79 & 664.26 & 129.03 & 0.00 & 2.00 \\
\hline TORA & 2091.00 & 2091.00 & 100.00 & 570.41 & 97.78 & - & - \\
& & & & & & & \\
\hline
\end{tabular}

TABLE-6 PERFORMANCE RATE (PACKET SIZE=1600BYTES, NO: OF NODES $=75$, MOBILITY=10.0MS)

\begin{tabular}{|l|l|l|l|l|l|l|l|}
\hline & PACKET & PACKET & PDF & $\begin{array}{l}\text { THROU } \\
\text { GHPUT }\end{array}$ & END-END & NRL & RO \\
SELCLIY & RECEIVE & & & & & \\
\hline AODV & 4300.00 & 4291.00 & 99.79 & 341.47 & 247.61 & 0.02 & 76.00 \\
\hline DSDV & 6053.00 & 5986.00 & 98.89 & 506.34 & 159.64 & 0.21 & $\begin{array}{l}1274 . \\
00\end{array}$ \\
\hline $\begin{array}{l}\text { DSR } \\
\text { TORA } \\
\text { nodes } \\
\text { nod }\end{array}$ & 3846.00 & 3845.00 & 99.97 & 662.92 & 131.87 & 0.00 & 2.00 \\
\hline
\end{tabular}

TABLE-7 PERFORMANCE RATE (PACKET SIZE=1600BYTES, No:OF NODES $=85$, MOBILITY=10.0MS)

\begin{tabular}{|l|l|l|l|l|l|l|l|}
\hline & PACKET & PACKET & PDF & $\begin{array}{l}\text { THROU } \\
\text { GHPUT }\end{array}$ & END-END & NRL & RO \\
\hline AODV & 6393.00 & 6381.00 & 99.81 & 507.78 & 171.73 & 0.03 & 174.00 \\
\hline DSDV & 5982.00 & 5955.00 & 99.55 & 502.82 & 122.79 & 0.26 & 1553.00 \\
\hline $\begin{array}{l}\text { DSR } \\
\text { RORA } \\
\text { nodes }\end{array}$ & 7924.00 & 7921.00 & 99.96 & 631.43 & 135.14 & 0.01 & 118.00 \\
\hline
\end{tabular}

TABLE-8 PERFORMANCE RATE (PACKET SIZE=1600BYTES, NO: OF NODES $=` 100$, MOBILITY=10.0MS)

\begin{tabular}{|l|l|l|l|l|l|l|l|}
\hline & PACKET & PACKET & PDF & $\begin{array}{l}\text { THROU } \\
\text { GHPUT }\end{array}$ & END-END & NRL & RO \\
\hline SENT & RECEIVE & & DELAY & & \\
\hline AODV & 8593.00 & 8574.00 & 99.78 & 682.30 & 135.67 & 0.01 & 100.00 \\
\hline DSDV & 7879.00 & 7871.00 & 99.90 & 625.98 & 133.86 & 0.23 & 1835.00 \\
\hline DSR & 8374.00 & 8361.00 & 99.84 & 665.09 & 132.37 & 0.03 & 2.00 \\
\hline
\end{tabular}

\section{CONCLUSION:}

From all the graphs and tables, the analysis concludes that, by increasing the nodes the performance of AODV, DSR and DSDV remains consistent in Packet Delivery Fraction (PDF). The Throughput of AODV, DSR and DSDV protocols toggles. End-to-End Delay increases with node count to 45 and latter it decreases. DSR is consistent in terms of Routing overhead but AODV is decreasing in comparison with DSDV. In TORA, the scalability factor does not work and it will not work for the shortest path computation. The performance of protocols concludes with minimum variance in the metrics when the nodes are between 25 and 55 and there is maximum variation in the metrics when the nodes are between 55 and 100 . 


\section{REFERENCES}

[1] Charles.E.Perkins, "Ad Hoc networking” 2008, ISBN 97881-317-2096-7.

[2] Abdul Hadi Abd Rahman, Zuriati Ahmad Zukarnain, "Performance Comparision of AODV, DSDV and I-DSDV Routing Protocols in Mobile Ad Hoc Networks", European Journal of Scientific Research, ISSN: 1450-216X, vol. 31, No. 4, (2009), pp.566-576.

[3] Asma Toteja, Raynees Gujral, Sunil Thalia, "Comparative performance Analysis of DSDV, AODV and DSR Routing Protocols in MANETs, using NS2", 2010 International Conference on Advances in computing Engineering, IEEE Computer Society.

[4] M.S Corson, A. Ephremides, "A Distributed routing algorithm for mobile wireless networks, ACM/bALTZER wireless networks 1 (1) (1995) 61-81.

[5] V.D.Park, M.S.Corson, "A highly adaptive distributed routing algorithm for mobile wireless networks, in: Proceedings of INFOCOM, April 1997.

[6] Tony Larson, Nicklas Hedman, " Routing protocols in Wireless Ad-Hoc networks- A simulation Study”, 1998.

[7] Bulent Tavil, "Mobile Ad Hoc Networks: Energy Efficient Real-Time Data Communications", 2006.

[8] Azzedine Boukerche, "Algorithms and Protocols for wireless, Mobile Ad Hoc Networks", 2008.

[9] Mohammad Ilyas, Richard C. Dorf,b, "The handbook of ad hoc wireless networks", 2003.
[10] D. C. Plummer, "An Ethernet Address Resolution Protocol: Or Converting Network Protocol Addresses to 48-bit Ethernet Address for Transmission on Ethernet Hardware", RFC 826, Nov 1982

[11] C. K. Toh, "A Novel Distributed Routing Protocol to support Ad Hoc Mobile Computing”, In proceedings of the 1996 IEEE Fifteenth Annual International Phoenix Conference on Computers and Communications, March 1996, 480-486.

[12] R. Dube, C. D. Rais, K. -Y. Wang, and S. K. Tripathi, "Signal Stability Based Adaptive Routing (SSA) for Ad Hoc Mobile Networks", IEEE Personal communications 4(1): 36-45, Feb 1997.

[13] C. Perkins and E. M. Royer, "Ad hoc On-demand distance vector routing", In proceedings of the second annual IEEE workshop on Mobile Computing Systems and Applications, Feb 1999, 90-100.

[14] Z.J Haas, "A New Routing Protocol for the Reconfigurable Wireless Networks", In Proceedings of the Sixth International Conference on Universal Personal Communications, October 1997, 562-566.

[15] Z.J. Haas and M.R. Pearlman, "The Performance of Query Control Schemes for the Zone Routing Protocol", In Proceedings of ACM SIGCOMM '98, September 1998, 167-177. 